\title{
Influence of panel fastening on the acoustic performance of light-weight building elements: study by sound transmission and laser scanning vibrometry
}

\author{
N.B. Roozen ${ }^{\mathrm{a}, *}$, H. Muellner ${ }^{\mathrm{b}}$, L. Labelle ${ }^{\mathrm{a}}$, M. Rychtárikováa, ${ }^{\mathrm{a}, \mathrm{c}}$, C. Glorieux ${ }^{\mathrm{a}}$ \\ ${ }^{a}$ Katholieke Universiteit Leuven, Laboratory of Acoustics, Soft Matter and Biophysics, \\ Department of Physics and Astronomy, Celestijnenlaan 200D 3001 Leuven, Belgium. \\ ${ }^{b}$ Federal Institute of Technology TGM, Department of Acoustics and Building Physics, \\ Vienna, Austria. \\ ${ }^{c}$ STU Bratislava,Department of Building Structures, Radlinskeho 11, Bratislava, 81005 , \\ Slovak Republic.
}

\begin{abstract}
Structural details and workmanship can cause considerable differences in sound insulation properties of timber frame partitions. In this study, the influence of panel fastening is investigated experimentally by means of standardized sound reduction index measurements, supported by detailed scanning laser Doppler vibrometry. In particular the effect of the number of screws used to fasten the panels to the studs, and the tightness of the screws, is studied using seven different configurations of lightweight timber frame building elements. In the frequency range from 300 to $4000 \mathrm{~Hz}$, differences in the weighted sound reduction index $R_{W}$ as large as 10dB were measured, suggesting that the method of fastening can have a large impact on the acoustic performance of building elements. Using the measured vibrational responses of the element, its acoustic radiation efficiency was computed numerically by means of a Rayleigh integral. The increased radiation efficiency partly explains the reduced sound reduction index. Loosening the screws, or reducing the number of screws, lowers the radiation efficiency, and

*Corresponding author, email: bert.roozen@kuleuven.be, tel: +32 16327840

Email addresses: bert.roozen@kuleuven.be (N.B. Roozen), hmuellner@tgm . ac .at (H. Muellner), ludovic.labelle@kuleuven.be (L. Labelle), monika.rychtarikova@kuleuven.be (M. Rychtáriková), christ.glorieux@kuleuven.be (C. Glorieux)
\end{abstract}


significantly increases the sound reduction index of the partition.

Keywords:

Laser Doppler vibrometry, sound transmission, sound insulation, light weight construction, panel fastening

\section{Introduction}

Lightweight construction building elements, e.g. timber frame partitions, show a large variation of sound insulation properties [1, 2] although many of them differ only in a few subtle details. The rather complex interactions around the element details require careful investigation, in particular to respond to the need for reliable prediction models. Several studies (e.g. [3, 4, 5, 6, 7]) have shown that workmanship has significant influence on the sound insulation characteristics of this kind of building elements. The used method to fasten (e.g. with screws or staples) the panel (e.g. gypsum boards, gypsum fiber boards or chipboards) to the studs has a considerable influence on the sound insulation characteristics, and thus on the single values that are commonly used for rating the acoustic insulation performance. Since element-related variations of the single numbers often exceed the range of typical sound insulation categories of proposed sound insulation classification schemes (i.e. [8, 9]), these uncertainties need to be quantified and indicated, together with the reported values.

In literature, numerous studies have been carried out on the sound transmission through double leaf wall systems. In ref. [10] it was found that structural connections greatly reduce the sound transmission loss, especially for wooden studs (and, to a lesser extent, for lightweight steel studs). The effect of nail spacing in wood-studded plasterboard double panels was also studied by Craik and Smith [11]. Decreasing the nail spacing produces systematically higher values of the sound reduction index, which was explained by the fact that when the nails are acoustically far apart (i.e. larger than half the bending wavelength of waves on the panel) then they can be considered as individual point connections whereas when they are close together the joint should be considered as a line connection. This was also verified in a study by Schoenwald [12] who used scanning laser vibrometry for that purpose. Similarly, Mayr and Gibbs [13] conclude that the point mobility of panels that are point-connected to frames, strongly depend upon the distance between the drive point considered and the nearest fixing points. When this distance is 
less than 0.2 times the bending wavelength of waves on the panel, the point mobility is determined by the framing elements. When this distance is larger, the frame fixings have minimal effect and the panels can be considered an infinite, unstiffened plate. Also ref. [14] reports that the stiffness (or type) of the stud, and the spacing of the screws between the panel and the stud are crucial parameters. Finally, in ref. [15] the effect of screw spacing was investigated for steel frame studs, considering two screw spacings of 300 and $600 \mathrm{~mm}$.

In this article, the workmanship related sound insulation uncertainties of a basic timber frame partition were investigated in detail. In particular, the effect of the number of screws, and how firmly the panel is fastened to the studs, on the sound reduction index $R$ of the lightweight building element was studied experimentally. Seven different configurations of a lightweight timber frame building element were considered, varying the srew spacings from $1230 \mathrm{~mm}$ down to $307.5 \mathrm{~mm}$, the screws being firmly fixed and subsequently loosened half a turn. Standardized sound insulation measurements according to ISO 10140 [16] were carried out and supported by scanning laser Doppler vibrometer (LDV) measurements.

The physical mechanisms involved were investigated with the aim to enhance the understanding of the interactions in the zones around the screws. Advanced data processing of the LDV measurement results was carried out, obtaining operational deflection shapes of the building element, the radiated sound power, and radiation efficiencies of the building element. With these findings the influence of the fastening details on the sound transmission index are explained from a physical point of view. This insight provides input to the development of prediction model details regarding the influence of crucial building element details on the sound insulation properties and their range of variation.

The paper is structured as follows. Section 2 describes the methods used, i.e. the measurement methods according to the standard, and the LDV measurement approach employed in this work. This section also discusses the way the LDV measurement data are processed. Section 3 elaborates on the measurement test set-ups and the lightweight timber framed building element under test. Section 4 presents the measurement results obtained by the measurements according to the standard (section 4.1) and the results obtained by the LDV measurements (section 4.2). In section 5 conclusions are drawn. 


\section{Methods}

\subsection{Measurement and analysis method according to ISO standards}

Sound transmission measurements were performed on a timber frame partition according to the standard ISO 10140 [16]. The sound pressure level of a diffuse sound field in the source room and in the receiving room was measured in one third octave bands from $50 \mathrm{~Hz}$ up to $5000 \mathrm{~Hz}$. A spatial average of the sound pressure levels was determined in source and receiving room by calculating the average across 2 microphone boom positions in each room, with an averaging period of $32 \mathrm{~s}$ at each boom position. During the averaging period of $32 \mathrm{~s}$, the boom completed one turn. The reverberation time of the receiving room (necessary for the calculation of the room compensation term and in calculation of the sound reduction index $R$ ) was measured as prescribed by the standard. Measurements were performed on 2 rotating microphone boom positions in each room.

Based on the one third octave band sound insulation values, the weighted sound reduction index $R_{W}$, as a single number quantity, is determined according to ISO 717-1 [17].

\subsection{Vibrometry based operational deflection shape analysis, sound power analysis and radiation efficiency analysis}

In the performed LDV measurements, the vibrational response of a timber frame partition due to a structure borne excitation, using a shaker connected to the panel, is measured as a function of position along the panel surface. A structure borne point excitation was employed in this measurement because, in principle, there is a relationship between airborne sound insulation and impact sound pressure level provided by partitions (see for instance [18, 19, 20]). This principle is valid both above and below the coincidence frequency, as was pointed out by Vér [19] and Beranek [21]. A more in-depth discussion on the measurement results as obtained by structure borne excitation and airborne excitation can be found in Section 4.2.5,

In addition, compared to excitation by an airborne incident acoustic wave, excitation by means of a shaker gives a better measurement quality for a number of reasons. Firstly because of the use of an impedance head between the shaker and the test wall, the acceleration at the point of excitation and the exciting force are measured, which both can be used as well defined reference signals. Secondly, the structure is excited in a deterministic manner at a single point, as opposed to a randomly distributed acoustic excitation. This 
approach allows the study of the vibration pattern of the panel surface and the determination of the acoustic radiation efficiency due to a point source excitation, revealing interesting effects of panel fastening, as will be discussed in Section 4 .

The vibrational response of the panel can be determined as a function of frequency by performing a Fourier transform from the time to the frequency domain,

$$
\tilde{v}\left(\mathbf{r}_{\mathbf{S}}, \omega\right)=\int_{-\infty}^{\infty} v\left(\mathbf{r}_{\mathbf{S}}, t\right) e^{-i \omega t} d t
$$

where $v\left(\mathbf{r}_{\mathbf{S}}, t\right)$ is the time dependent velocity at position $\mathbf{r}_{\mathbf{S}}=(x, y)$ along the panel with area $S$, in normal direction of the panel, where $\tilde{v}\left(\mathbf{r}_{\mathbf{S}}, \omega\right)$ is the velocity as function of $\mathbf{r}_{\mathbf{S}}$ and as function of angular frequency $\omega$, and where $\mathrm{i}=\sqrt{-1}$ is the imaginary unit. Note that the tilde ${ }^{\sim}$ denotes frequency domain. The radiated sound power and the radiation efficiency of the structure as a function of frequency can be determined from $\tilde{v}\left(\mathbf{r}_{\mathbf{S}}, \omega\right)$ numerically.

Physically speaking, the plate dynamically couples to the room by acoustic radiating into the air and vice versa. This coupling is especially effective when the plate waves are supersonic with respect to the speed of sound in air, which happens at the coincidence frequency and above (in the present case at or above $2500 \mathrm{~Hz}$, as will be discussed later). Even though at low frequencies the efficiency of radiation is relatively poor, it is know 22 that at low frequencies room acoustic modes of the receiving room do influence the measured sound reduction index and radiation efficiency of a building element. In this work we are mainly interested in this low frequency range (below the coincidence frequency), meaning that for an exact computation of the radiated sound power, we should take into account the geometry of the receiving room and its damping (reverberation).

However, there are two reasons not to take the room acoustics of the receiving room into account. By virtue of the fact that in this work we are mainly interested in the differences in the acoustic radiation between the partition configurations studied, it is sufficient to use a model in which it is assumed that the building element is mounted in a baffle, and is radiating into a semi-infinite acoustic domain. This excludes the influence of the acoustics of the receiving room. Another reason is that classical microphone based methods to measure the radiated sound power are hampered by room acoustical effects at low frequencies. Computing the radiated sound power 
from the laser Doppler vibrometry measurement data, assuming a free field radiation, circumvents the problems related to the non-diffuse sound fields and modal coupling effects in the receiving room at low frequencies [23]. In this way the intrinsic sound transmission properties of the building element can be assessed, without the disruptive effects of the room acoustics of the receiving rooms at low frequencies.

The acoustic radiation into a semi-infinite acoustic domain is described by the Rayleigh integral model that was developed over a century ago [24], and provides a simple but exact representation for the sound radiated from a flat vibrating surface mounted on an infinite rigid baffle. The theory has been elaborated in detail in text books [25] and literature [26], and is briefly summarized below.

Following ref. [25, 26] the acoustic pressure $\tilde{p}$ can be written as

$$
\tilde{p}(\mathbf{r}, \omega)=\frac{i \omega \rho}{2 \pi} \iint_{S} \tilde{v}\left(\mathbf{r}_{\mathbf{S}}, \omega\right) \frac{e^{-\mathrm{i} k \mathcal{R}}}{\mathcal{R}} d S
$$

where $\tilde{p}(\mathbf{r}, \omega)$ is the complex sound pressure at $\mathbf{r}$, the position vector at which the pressure is to be determined, $S$ denotes the area of the radiating structrure, $\mathbf{r}_{\mathrm{S}}$ is the position vector on the surface $S, \mathcal{R}$ is the distance between $\mathbf{r}$ and $\mathbf{r}_{\mathbf{S}}, \tilde{v}\left(\mathbf{r}_{\mathbf{S}}, \omega\right)$ is the velocity in normal direction at position $\mathbf{r}_{\mathbf{S}}$, $\rho$ is the density of air, $\omega$ is the angular frequency of the plate vibration, $c$ is the speed of sound in air, and $k=\frac{\omega}{c}$ is the wave number.

The active acoustic intensity $\tilde{I}$ along the surface $S$ of the vibrating panel, in normal direction of the panel, can be obtained as

$$
\tilde{I}\left(\mathbf{r}_{\mathbf{S}}, \omega\right)=\frac{1}{2} \operatorname{Re}\left[\tilde{p}\left(\mathbf{r}_{\mathbf{S}}, \omega\right) \tilde{v}^{*}\left(\mathbf{r}_{\mathbf{S}}, \omega\right)\right]
$$

where $\operatorname{Re}(\cdots)$ denotes the real part of a complex quantity and the asterisk denotes the complex conjugate.

The total radiated active sound power $\tilde{W}$ can be obtained by integrating the active acoustic intensity $\tilde{I}$ over the surface $S$.

$$
\tilde{W}(\omega)=\iint_{S} \tilde{I}\left(\mathbf{r}_{\mathbf{S}}, \omega\right) d S
$$

A commonly used measure of the sound radiation characteristics is the radiation efficiency $\sigma$, which is defined as the ratio of power radiated by the structure being considered, to that of a reference structure 


$$
\sigma(\omega)=\frac{\tilde{W}(\omega)}{\widetilde{W}(\omega)}
$$

where $\widetilde{W}$ is the power that would be radiated by a uniformly vibrating baffled piston of the same area $S$ and with velocity $\sqrt{\left\langle\tilde{v}_{n}^{2}\right\rangle}$ equal to the average mean square velocity of the structure in normal direction being considered:

$$
\widetilde{W}=\frac{1}{2} \rho c S\left\langle\tilde{v}_{n}^{2}\right\rangle
$$

Combining Eq. (5) and Eq. (6) yields

$$
\sigma(\omega)=\frac{\tilde{W}(\omega)}{\frac{1}{2} \rho c S\left\langle\tilde{v}_{n}^{2}(\omega)\right\rangle}
$$

\subsection{Measurements of the mechanically injected power}

In the performed LDV measurements the building element was excited at a single point of the panel by means of a shaker. The exciting force and the resulting acceleration were measured by means of an impedance head. Following Verheij [27], the time averaged injected mechanical power $\left\langle P_{m}\right\rangle_{t}$ can be calculated as follows

$$
\left\langle P_{m}\right\rangle_{t}=\langle F v\rangle_{t}=\int_{0}^{\infty} \frac{\operatorname{Im}(\tilde{G}(F, a, \omega))}{\omega} d f
$$

where $\langle\cdots\rangle_{t}$ denotes time averaging, $F$ is the measured force, $a$ the measured acceleration, $v$ is the velocity, $\tilde{G}(F, a, \omega)$ is the cross-spectral density between the measured force and the measured acceleration in frequency domain, and $\operatorname{Im}(\cdots)$ denotes the imaginary part.

\subsection{Dispersion analysis}

After transforming the LDV measurement data from time domain to frequency domain (Eq. (1)), the LDV measurement data was transformed from the spatial $\mathbf{r}=(x, y)$ domain to the wavenumber domain $\mathbf{k}=\left(k_{x}, k_{y}\right)$ by means of a two-dimensional spatial Fourier transform,

$$
\hat{\tilde{v}}(\mathbf{k}, \omega)=\iint_{S} \tilde{v}(\mathbf{r}, \omega) e^{-2 \pi \mathrm{i} \mathbf{k} \cdot \mathbf{r}} d S,
$$


where $\mathbf{k}$ is the wavenumber vector. In case we are dealing with a rectangular surface $S$ of dimension $L_{x}$ and $L_{x}$, in $x$ - and $y$ - direction, respectively, this equation reads:

$$
\hat{\tilde{v}}(\mathbf{k}, \omega)=\int_{x=0}^{L_{x}} \int_{y=0}^{L_{y}} \tilde{v}(\mathbf{r}, \omega) e^{-i 2 \pi k_{x} x} e^{-i 2 \pi k_{y} y} d x d y
$$

The propagation velocities $c_{x}$ and $c_{y}$, in $x$ - and $y$ - direction, as function of frequency, can be calculated from

$$
c_{x}=\operatorname{Re}\left(k_{x} / \omega\right)
$$

and

$$
c_{y}=\operatorname{Re}\left(k_{y} / \omega\right) \text {, }
$$

respectively, where $\mathbf{k}$ can be found from the maximum values of $|\hat{\tilde{v}}(\mathbf{r}, \mathbf{k})|$, thus relating $\mathbf{k}$ and $\omega$ for a specific mode found.

\section{Experimental setup}

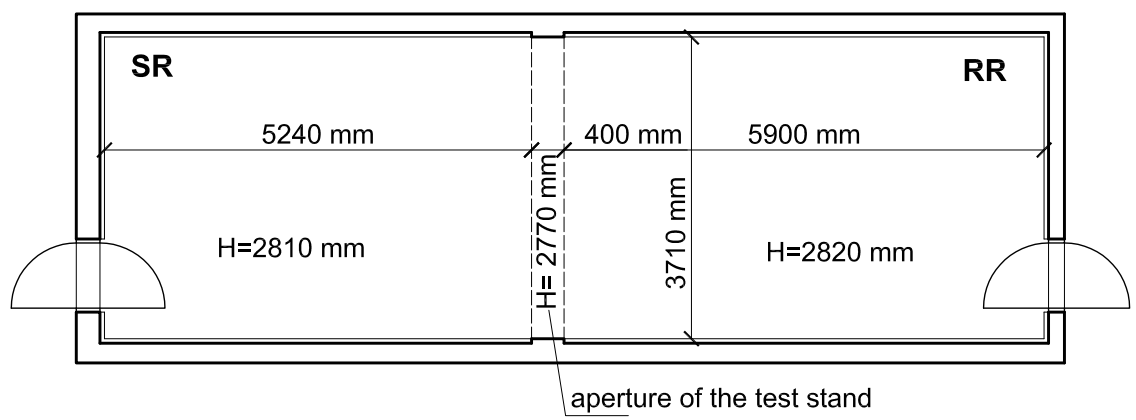

Figure 1: Layout of the test facility for airborne sound insulation measurements at TGM, Vienna, according to ISO 10140. $\mathrm{SR}=$ source room, $\mathrm{RR}=$ receiving room.

The experiments were carried out in a test stand for airborne sound insulation measurements at TGM, Vienna (see Fig. 1), according to ISO 10140-5 [16]. 


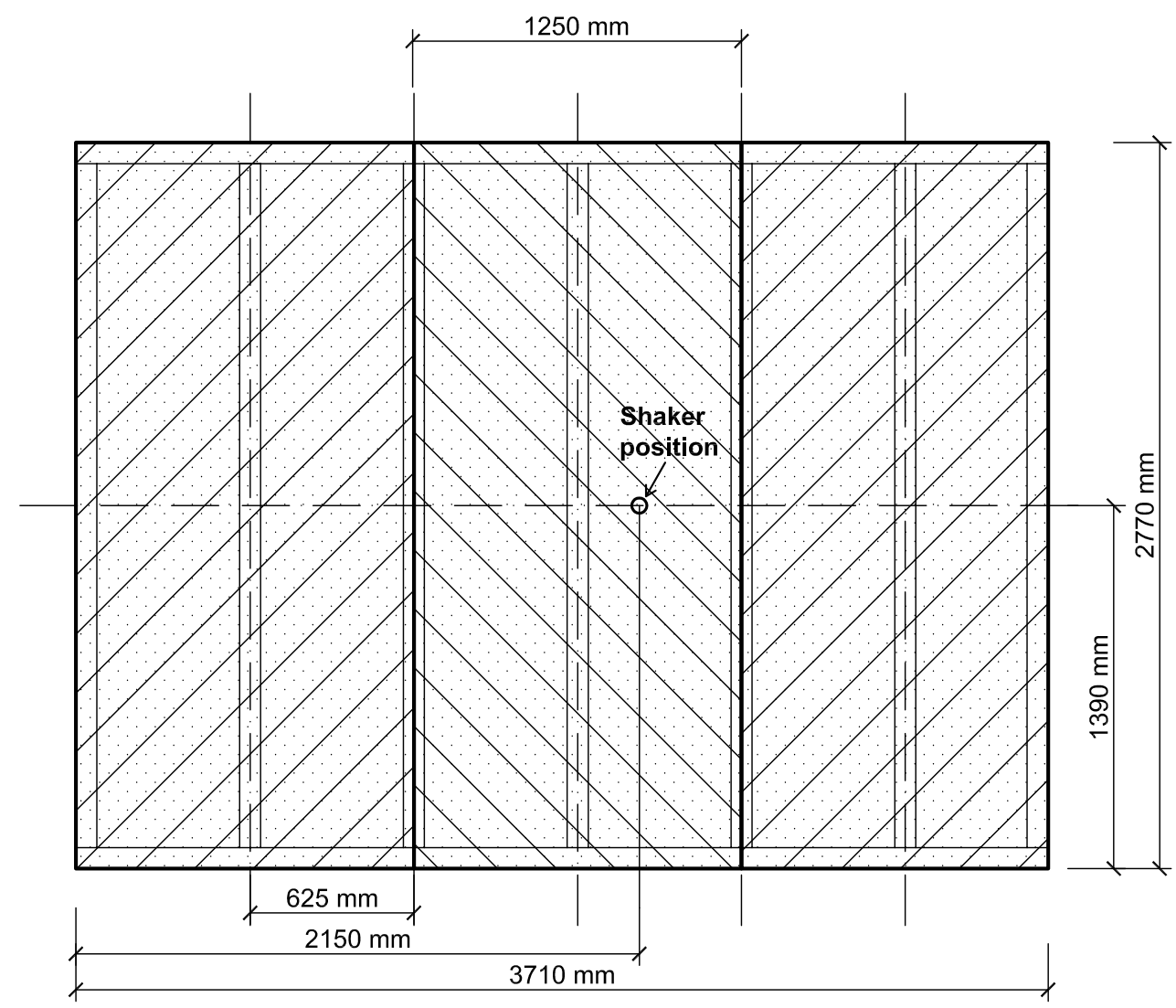

Figure 2: View of the timber frame partition, arrangement of the studs and the gypsum fiber boards, three in total. Position of shaker excitation indicted.

\subsection{Description of the investigated structure and mounting configurations}

All measurements were performed on the light weight structure (timber frame partition) depicted in Fig. 2. The test specimen was mounted into the test opening with dimensions $2770 \mathrm{~mm}$ (height) and $3710 \mathrm{~mm}$ (width) (total surface area of $10.4 \mathrm{~m}^{2}$ ).

The timber frame consisted of timber studs of $160 \mathrm{~mm} / 80 \mathrm{~mm}$ section. The studs were mounted $625 \mathrm{~mm}$ off-centre distance to each other. On both sides $12.5 \mathrm{~mm}$ gypsum fiber boards (three in total on each side, arrangement c.f. Fig. 2) with dimensions of $2760 \mathrm{~mm} \times 1250 \mathrm{~mm}$ were fixed by screws (diameter $3.9 \mathrm{~mm}$, length $45 \mathrm{~mm}$ ). The space between the two boards was entirely filled with glass wool of $12.5 \mathrm{kgm}^{-3}$ density. Fig. 3 shows the horizontal section of a part of the partition. 


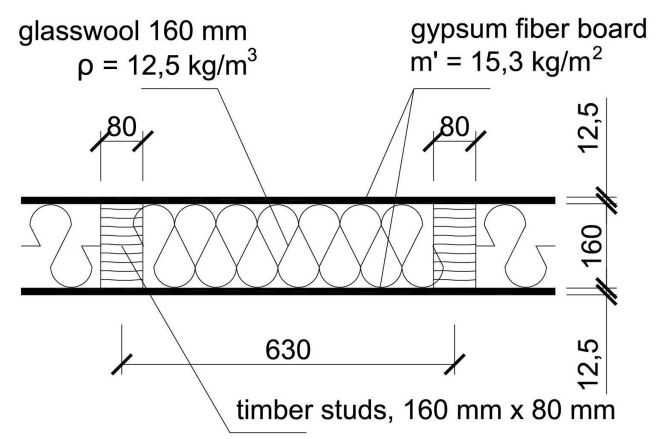

Figure 3: Horizontal section of the test specimen.

The butt joints of the gypsum fiber boards were sealed by applying a jointing compound (a gypsumpowder with a defined delay in becoming rigid, allowing some time for erecting the structure), thus resulting in a continuous board covering the whole test area, without slits in between the gypsum fiber boards. The mechanical properties of the jointing compound closely resembled the mechanical properties of the gypsum fiber boards. An acrylic seal was used between the boards and the concrete walls of the test facility, all along the perimeter, to prevent acoustic leaks.

This timber frame partition can be considered as a kind of basic construction of many timber frame configurations of partitions between dwellings but also of outer walls. The expected airborne sound insulation property is roughly in the range of central standard sound insulation requirement categories of many European countries [28]. Thus this partition serves as a

\begin{tabular}{|l|l|l|}
\hline \multicolumn{2}{|l|}{ Timber frame configuration } \\
\hline \hline 1 & screws at the bottom and top only & \\
2 & one row of screws in the middle, $\mathrm{d}=1230 \mathrm{~mm}$ & firmly fixed \\
3 & three rows of screws, $\mathrm{d}=615 \mathrm{~mm}$ & firmly fixed \\
4 & seven rows of screws, $\mathrm{d}=307.5 \mathrm{~mm}$ & firmly fixed \\
5 & seven rows of screws, d $=307.5 \mathrm{~mm}$ & $\frac{1}{2}$ turn loosened \\
6 & three rows of screws, d $=615 \mathrm{~mm}$ & $\frac{1}{2}$ turn loosened \\
7 & one row of screws in the middle, d = $1230 \mathrm{~mm}$ & $\frac{1}{2}$ turn loosened \\
8 & screws at the bottom and top only, repeat of 1 & \\
\hline
\end{tabular}

Table 1: Screw configurations. 
relevant example both from a practical and experimental point of view.
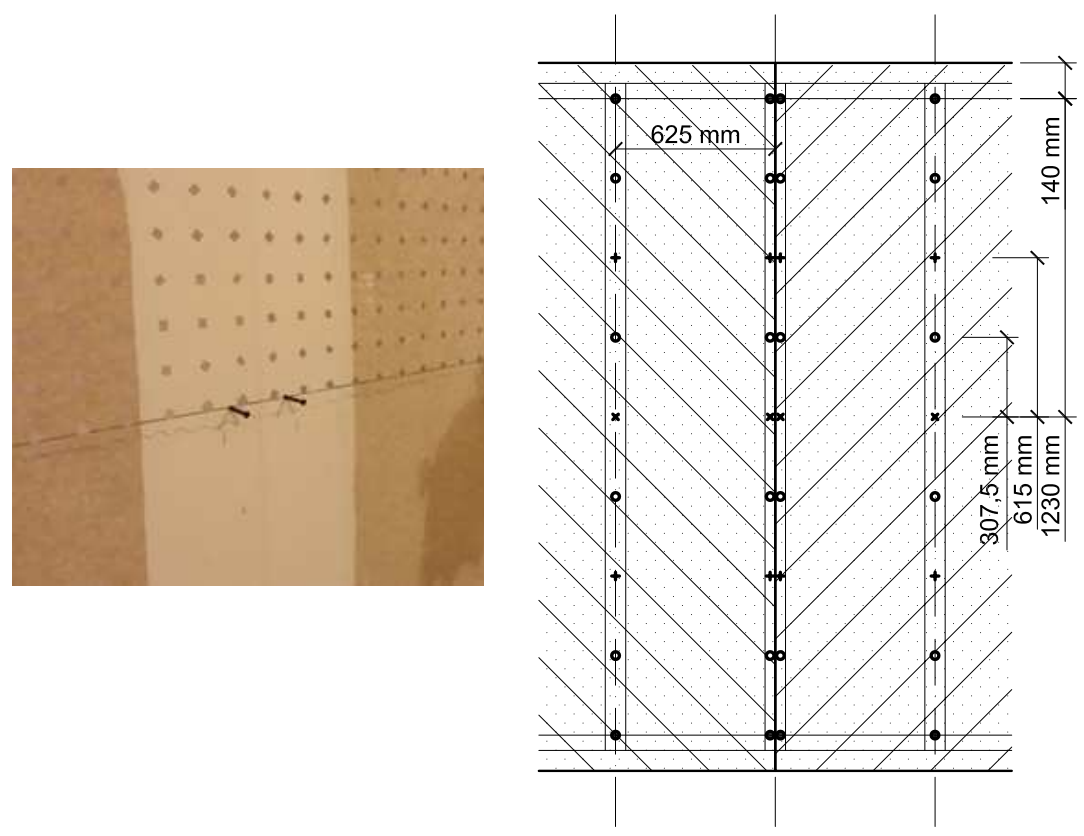

(a)

(b)

Figure 4: Arrangement of the screws. (a) Photograph of screws to be mounted; (b) mounting details of the gypsum fiber boards, where the following symbols where used to indicate the different configurations: The filled circles were the "very first" screws, which were kept in all configurations. x: row of screws added for configuration 2. +: row of screws added for configuration 3. o: row of screws added for configuration 4 . See also Table 1 for a listing of all configurations.

The panels were fastened with screws in different configurations, as listed in Table 1 and shown in Fig. 4. For the first configuration, the gypsum fiber boards were only fixed in each corner by screws at the top and at the bottom of the stud, at a minimum distance of $140 \mathrm{~mm}$ off the panels edge. For the second configuration screws were added on the height of the horizontal center line (1385 $\mathrm{mm}$ from the bottom and the top respectively, and with $1230 \mathrm{~mm}$ distance from the screws at the top and at the bottom). For configuration 3 , three rows of screws were used, with a distance of $615 \mathrm{~mm}$ between the rows. For configuration 4, seven rows of screws were used, with a distance of $307.5 \mathrm{~mm}$ between the rows. In the previous configurations the screws were firmly fixed, using a torque approximately between 1 and $5 \mathrm{Nm}$. 
For configurations 5 to 7 the screws were slightly loosened by one halve turn. Configuration 8, which was measured after completing the measurements for all other configurations, was the same as configuration 1 which was measured at the very beginning.

Note that at the position where the gypsum fiber board butts are jointed by means of a dedicated jointing compound, a double column of screws were used for the connection of the boards to the studs, whilst for the stud positions that are not located at such a butt joint only one column of screws was used (c.f. Fig. 4).

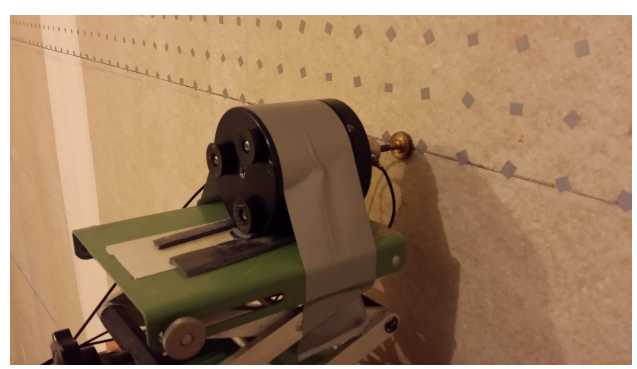

(a)

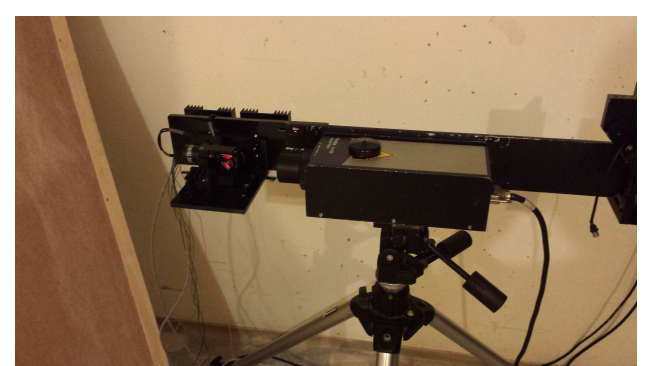

(b)

Figure 5: Measurement equipment. (a) Shaker that was used to excite the wall; (b) scanning laser Doppler vibrometer (developed in-house).

\subsection{Laser Doppler vibrometry measurement set-up}

A Bruel\&Kjaer mini-shaker type 4810 was used to excite the panel mechanically, as shown in Fig. 5(a), Its position is indicated in Fig. 2, The shaker was driven by band limited white noise with a frequency range up to $3000 \mathrm{~Hz}$. It was mounted on the vertical symmetry line of the light-weight structure, between two studs as shown in Fig. 2, at the receiving side of the panel using a short stinger. The shaker excitation was the only excitation during this experiment. The response of the structure was measured on the same "receive" side of the panel (thus excitation and response measurement is on the same side). The response was measured by means of a scanning laser Doppler vibrometer, as shown in Fig. 5(b). This measurement system comprises a single head laser Doppler vibrometer from Polytec (OFV-505 head and OFV-5000 controller), with a scanning system, developed in-house, which is based upon a dual-axis mirror from Thorlabs. In horizontal direction the symmetry of the wall (and its timber frames) was not perfect due to 


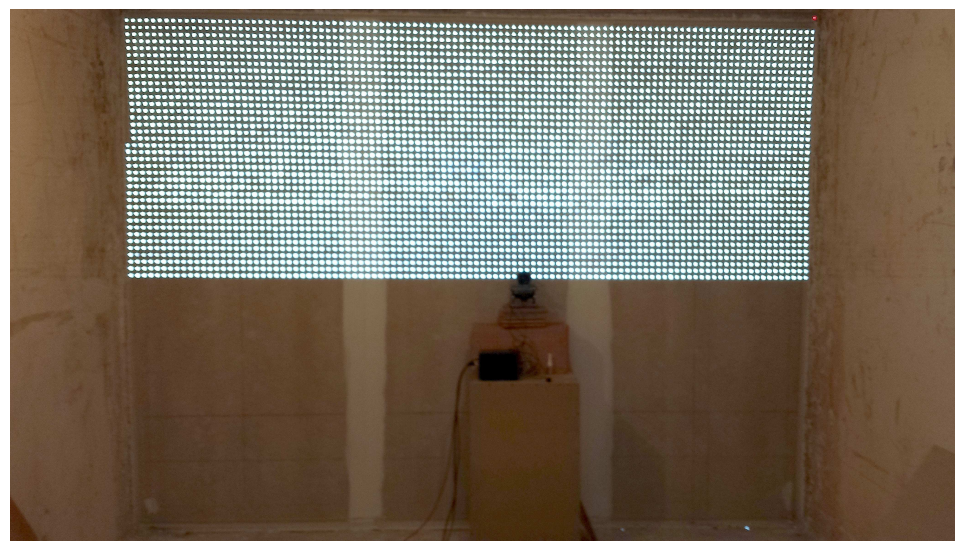

Figure 6: Light-weight double wall under test (width: $3710 \mathrm{~mm}$, height: 2770 $\mathrm{mm}$ ), pieces of retro-reflecting tape stuck on to the upper part of the wall, photo made with flash (which puts emphasis on the pieces of retro-reflecting tape).

craftsmen ship tolerances. However, in the vertical direction the symmetry line could be determined within a few mm accuracy relative to the floor and the ceiling of the test facility. By exciting on this symmetry line, responses of the structure that are symmetric in vertical direction are expected, thus allowing the measurements to be limited to only one half of the structure without loss of information.

Preliminary measurements, using shaker excitation and measuring the response of the boards along the symmetry line, indicated that the wavelength for bending waves at $1000 \mathrm{~Hz}$ is approximately $200 \mathrm{~mm}$ (details of the measurement procedure will be discussed in section 4.2.1). For practical reasons the frequency range of interest is limited to $3000 \mathrm{~Hz}$. At this frequency the structural bending wavelength will be about $200 \mathrm{~mm} / \sqrt{3000 / 1000}=$ $110 \mathrm{~mm}$, employing the basic property of the bending wavelength to be inversely proportional to $\sqrt{f}$, where $f$ is the frequency [20]. According to Nyquist, a spatial sampling of about $50 \mathrm{~mm}$ is thus required. In order to allow an accurate determination of the velocity patterns, it was decided to use a spatial sampling of $35 \mathrm{~mm}$. Obviously the spatial sampling can be expanded when lowering the frequency range of interest.

In order to achieve sufficient optical reflection, which is required to obtain good quality LDV signals, pieces of retro-reflecting tape were stuck on to the light-weight structure at every $35 \mathrm{~mm}$ in both horizontal and vertical directions, resulting in a grid of 107 (horizontal) x 39 (vertical) points, 4173 
points in total (Fig. 6). Measurements were performed at a sample rate of $25000 \mathrm{~Hz}$, using 10 averages of records of 2 seconds.

\subsection{Impedance head measurement set-up}

The exciting force and the resulting acceleration at the point of excitation was measured by means of a Bruel\&Kjaer impedance head, type 8001 . A short stinger was used.

\section{Results and analysis}

\subsection{Measurements of the sound reduction index}

The measured sound reduction index $R$ for 7 investigated configurations as a function of frequency, following ISO 10140-2 [16], is shown in Fig. 7.

Figure 7 reveals that the arrangement of the screws and the tightness with which they are fixed, has a considerable influence on the airborne sound insulation properties of the partition.

Configurations differ up to $15 \mathrm{~dB}$, mainly in frequency range from 300 - $4000 \mathrm{~Hz}$. However, at low frequencies $(<100 \mathrm{~Hz})$ an increased uncertainty of the standardized sound insulation measurements has to be expected due to a reduction in the number of room modes.

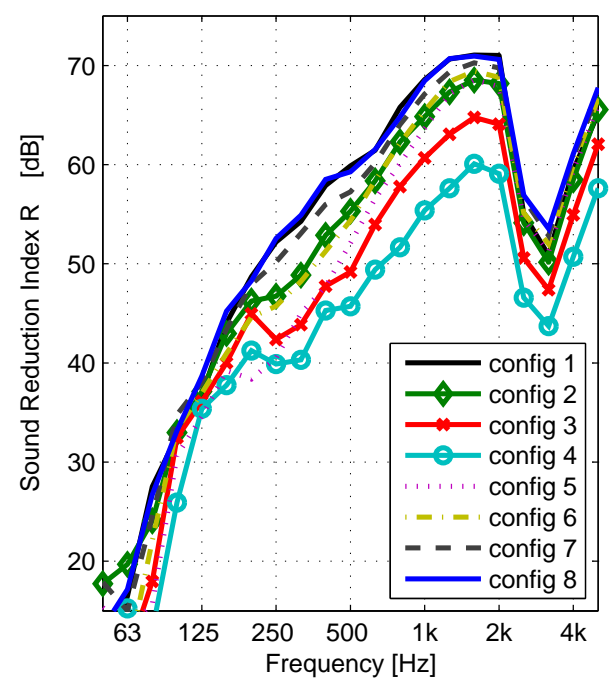

\begin{tabular}{|l|l|l|}
\hline \multicolumn{2}{|l|}{ Timber frame configuration } & Rw $(\mathrm{C} ; \mathrm{Ctr})$ \\
\hline \hline 1 & screws at bottom and top only & $58(-3 ;-7)$ \\
2 & one row, firmly fixed & $56(-2 ;-7)$ \\
3 & three rows, firmly fixed & $52(-1 ;-4)$ \\
4 & seven rows, firmly fixed & $48(-1 ;-5)$ \\
5 & seven rows, $\frac{1}{2}$ turn loosened & $52(-1 ;-8)$ \\
6 & three rows, $\frac{1}{2}$ turn loosened & $56(-2 ;-6)$ \\
7 & one row, $\frac{1}{2}$ turn loosened & $58(-2 ;-6)$ \\
8 & screws at bottom and top only & $59(-3 ;-8)$ \\
\hline
\end{tabular}

Figure 7 \& Table 2: Sound reduction index $\mathrm{R}$ and single number ratings of partition with different screw configurations. 
The weighted sound reduction index $R_{W}$ and the spectrum adaptation terms $C, C_{t r}$ were determined according to ISO 717-1 [17]. The single number quantities characterizing the sound insulation properties are listed in Table 2 .

The difference between the best and worst configuration was $11 \mathrm{~dB}$ in case of $R_{W}$, (standard deviation between the different configurations was $3.9 \mathrm{~dB})$. In case of $R_{W}+C$ and $R_{W}+C_{t r}$ were the differences between the best and worse case $9 \mathrm{~dB}$ with standard deviation of $3.4 \mathrm{~dB}$. Configurations 1 and 7 (i.e. with screws at the bottom and top only and with one row of screws in the middle, loosened) showed the greatest insulation in all single number ratings $\left(R_{W}, R_{W}+C, R_{W}+C_{t r}\right)$. Configuration No. 4 (with seven rows of screws) has scored in all single number ratings as the worse one.

Interestingly, the case with seven rows of 'loosened' screws (configuration 5) gives the same single number rating as the case with 3 rows of tightly fixed screws (configuration 3) with $R_{W}=52 \mathrm{~dB}$ and analogously the situation with only one row of firmly placed screws (configuration 2 ) gives the same rating as the configuration 6 , with 3 rows of loosened screws $\left(R_{W}=56 \mathrm{~dB}\right)$.

\subsection{Laser Doppler vibrometry measurement results}

The next section shows how dispersion method can be used to estimate the material properties of the panels of the partition employing laser Doppler vibrometry measurements. Section 4.2.2 elaborates on the sound radiated by the partition due to structure borne excitation by means of a shaker, again using LDV measurement data. Section 4.2.3 shows operational deflection shapes of the partition and Section 4.2.4 elaborates on the mechanically injected power.

Although the laser Doppler vibrometry measurements employed a structure borne excitation at a single point by means of a shaker, it can reveal interesting aspects that also apply to airborne excitation properties of the partition by virtue of the relationship between airborne sound insulation and impact sound pressure level provided by partitions (see for instance [18, 19, 20, 21]). Such a relationship also exist below the coincidence frequency [19], and will be discussed in more detail in Section 4.2.5.

\subsubsection{Dispersion results}

Figure 8 shows a plot of the velocity in the wavenumber domain, $\hat{\tilde{v}}(\mathbf{k}, \omega)$, as determined according to Eq. (10), for configuration 1 at two frequencies, $f=\frac{\omega}{2 \pi}=1000 \mathrm{~Hz}$ and $2000 \mathrm{~Hz}$. The wavenumber domain plots for the other 


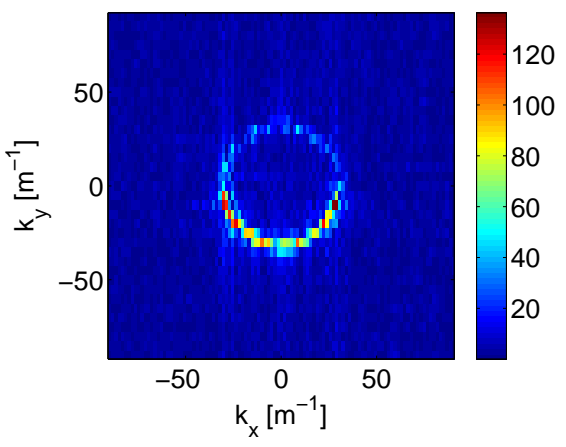

(a)

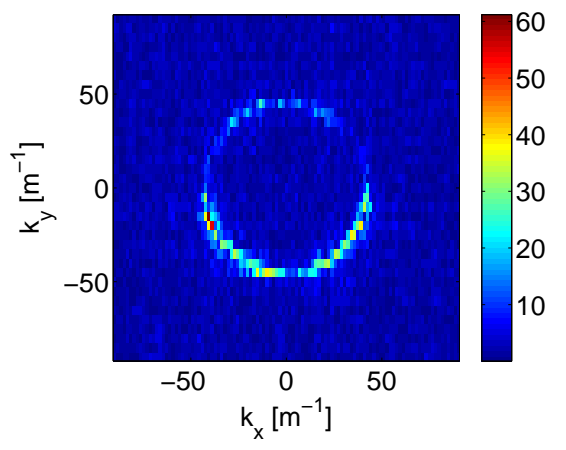

(b)

Figure 8: Dispersion plot for configuration 1, showing $\hat{\tilde{v}}(\mathbf{k}, \omega)$ (Eq. 10p) on a logarithmic scale $\left(\log _{10}\right.$ of the absolute value of $\hat{\tilde{v}}(\mathbf{k}, \omega)$, arbitrary unit). (a) Frequency $=1000 \mathrm{~Hz}$; (b) frequency $=2000 \mathrm{~Hz}$.

configurations and other frequencies are very similar. The plots clearly show circular rings, indicating that the waves propagate at the same velocity in all directions. The wavenumber domain components with negative $k_{y}$ values are more dominantly present, which suggests that the propagation in the positive $y$-direction (away from the shaker) was a bit stronger than for the negative $y$-direction (towards the shaker) due to dissipation effects. Note that only the upper half of the panel was measured and the shaker was placed at the lower side, implying that waves that propagate in negative $y$-direction are solely a result of waves that are reflected by the nearby ceiling. The wavenumber components in positive and negative $x$-direction are about equal, which is logical as the waves propagate away from from the shaker equally strong in positive $x$ and negative $x$-directions, due to the analysed horizontal scanning range having been chosen symmetrically around the shaker (but not exactly symmetric; see Fig. 2 and Fig. 6). The existence of a single wavenumber indicates that in this experiment only flexural bending waves (Lamb A0 mode) were efficiently excited, but no symmetric or high order modes.

Fitting an ellipse through the wavenumber domain results for each measured frequency, using a weighted linear least squares fit (see Appendix A), gives an estimate of the wavenumber of the waves propagating in $\mathrm{x}$ - and $\mathrm{y}$ direction as a function of frequency, shown in Fig. 9(a) for configuration 1. In this fit it was assumed that the ellipses have their origin at $\left(k_{x}, k_{y}\right)=(0,0)$ 


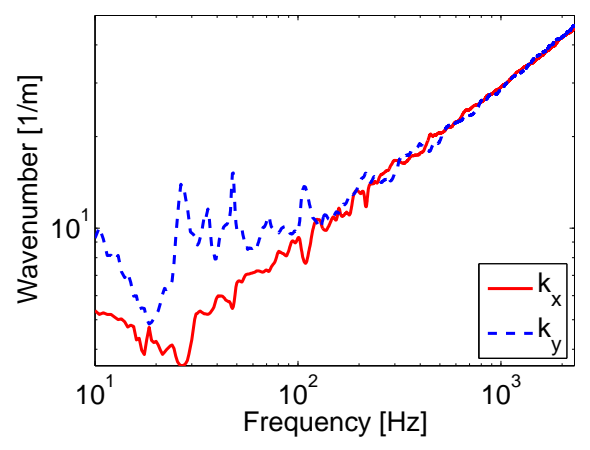

(a)

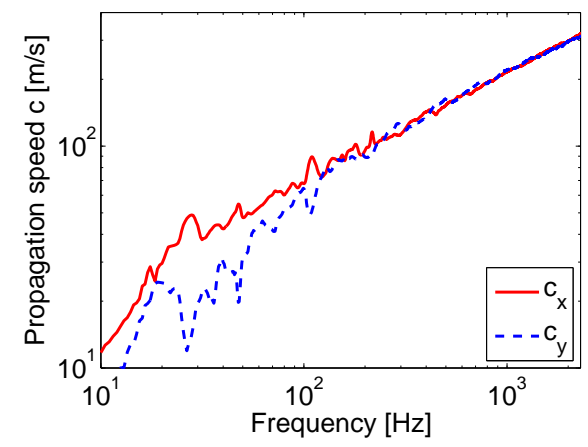

(b)

Figure 9: Horizontal and vertical dispersion data obtained by fitting ellipses to the $2 \mathrm{D}$ dispersion data in Figure 8. (a) Wavenumbers $k_{x}$ and $k_{y}$; (b) propagation velocities $c_{x}$ and $c_{y}$.

and that the principle axes of the ellipses are the $\mathrm{x}$ - and $\mathrm{y}$-directions, allowing for the estimation of orthotropic material behavior along the $\mathrm{x}$ - and $\mathrm{y}$-axes. The frequency dependent weighting factors on the diagonal of weighting matrix $W$ in Eq. A.5 were chosen to be the absolute values cubed of $\hat{\tilde{v}}(\mathbf{k}, \omega)$ (Eq. (10), and leaving out all measured values of $\hat{\tilde{v}}(\mathbf{k}, \omega)$ smaller than 10 times the maximum of $\hat{\tilde{v}}(\mathbf{k}, \omega)$. The propagation velocities $c_{x}$ and $c_{y}$ were calculated by means of Eq. (11) and Eq. (12), respectively. The results are shown in Fig. 9(b) for configuration 1. The propagation velocity turns out to be independent of the propagation direction within experimental uncertainty, inferring perfect elastic isotropy of the gypsum fiber board. Such isotropic behavior was also found for all other configurations. Apparently, the material stress induced by firmly screwing the gypsum fiber board is too weak to induce elastic anisotropy.

The elastic parameters of the gypsum board walls were found by fitting a bending wave model to the measured frequency dependence of the bending wave phase velocity data (Fig. 9(b)). A similar approach was applied by Nightingale to a wood joist floor [29]. For this purpuse a bending wave model is used for which the bending velocity $c_{B}$ is given by [20]:

$$
c_{B}=\left(\frac{B \omega^{2}}{m^{\prime \prime}}\right)^{1 / 4}
$$

where $B$ is the bending stiffness, $B=\frac{E h^{3}}{12\left(1-\nu^{2}\right)}$, with $E$ Young's modulus, $h$ 


\begin{tabular}{|lr|l|l|}
\hline \multicolumn{2}{|l|}{$\begin{array}{l}\text { Physical } \\
\text { property }\end{array}$} & $\begin{array}{l}\text { Fit result } \\
\text { in x-direction }\end{array}$ & $\begin{array}{l}\text { Fit result } \\
\text { in y-direction }\end{array}$ \\
\hline$c_{L}$ & {$\left[\mathrm{~ms}^{-1}\right]$} & 2550 & 2525 \\
$c_{T}$ & {$\left[\mathrm{~ms}^{-1}\right]$} & 1170 & 1160 \\
$E$ & {$\left[\mathrm{Nm}^{-2}\right]$} & $4.47 \cdot 10^{9} \pm 0.3 \cdot 10^{9}$ & $4.37 \cdot 10^{9} \pm 0.5 \cdot 10^{9}$ \\
\hline
\end{tabular}

Table 3: Fit results using a bending wave model.

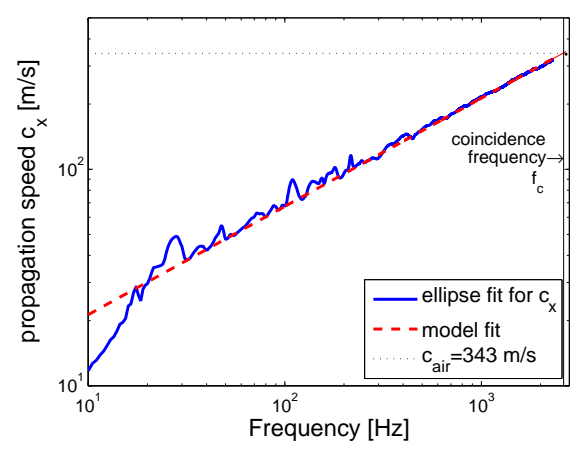

(a)

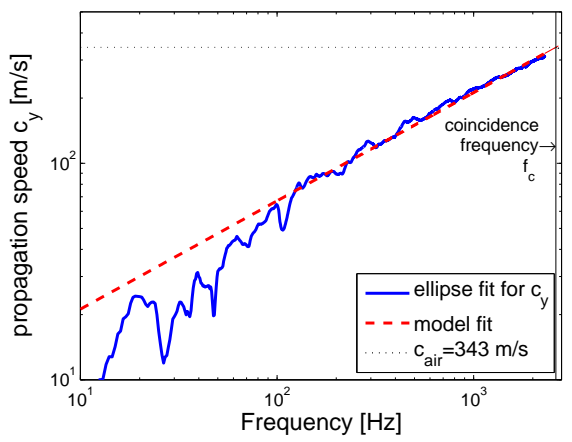

(b)

Figure 10: Experimental values (solid line, taken from Figure $9(\mathrm{~b})$ and fit (dashed curves) for the frequency dependence of the bending wave propagation. The theoretical speed of sound (dotted curve) is indicated, as well as the coincidence frequency $f_{c}$. (a) $x$-direction; (b) $y$-direction.

the thickness of the wall $(12.5 \mathrm{~mm}), \nu$ Poisson's ratio, and $m^{\prime \prime}$ is the mass per unit surface area, $m^{\prime \prime}=\rho h$ with $\rho$ the mass density of the wall. Equation 13 is valid if the bending wavelength is large compared to the dimensions of the cross-section of the plate. In addition, rotational energy contributions are ignored, which is reasonable for thin plates.

Fitting the measurement data for configuration 1 on to the bending wave model, optimizing for the Young's modulus $E$ in a least squares sense, gives the estimates listed in Table 3. Fits of the frequency dependence of the propagation velocities $c_{x}$ and $c_{y}$ are shown in Fig. 10. The fit on the bending wave model requires knowledge about the density $\rho$ and the Poisson's ratio $\nu$. The weight of the gypsum fibre boards were measured before installation of the boards, from which it followed that the density $\rho$ was equal to 1224 $\mathrm{kgm}^{-3}$. The Poisson's ratio $\nu$ is assumed to be equal to 0.3 , which seems to 


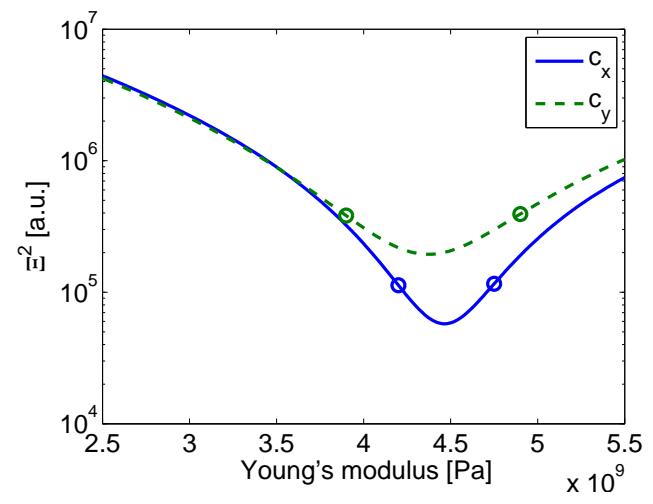

Figure 11: The residue $\Xi=\sum_{f=0}^{f=f_{\max }}\left(c_{B}(f)-c_{\text {measured }}(f)\right)^{2}$, as function of Young's modulus $E$. The small circles indicate residuals $\Xi$ which are a factor 2 larger than the minimum residual.

be a reasonable value (e.g. see [30]). The residual that is minimized in the optimization is defined as $\Xi=\sum_{f=0}^{f=f_{\max }}\left(c_{B}(f)-c_{\text {measured }}(f)\right)^{2}$, where $c_{B}$ is the predicted propagation speed (Eq. (13)) and $c_{\text {measured }}$ is the measured propagation speed (in either the $x$ - or the $y$ - direction) as function of frequency $f$, summing up at discrete frequencies up to $f_{\max }=2300 \mathrm{~Hz}$, in frequency steps of $0.5 \mathrm{~Hz}$. Figure 11 shows the residual as function of the Young's modulus $E$, for the measurement data in $x$ - and in $y$ - direction. The limits of uncertainty can be determined by considering the values of the Young's modulus $E$, for which the residual $\Xi$ is a factor 2 larger than the minimum residual [31] (indicated by small circles in Fig. 11), resulting in the uncertainties in the Young's modulus as listed in Table 3.

The values found for Youngs modulus $\mathrm{E}$ are within the range of values (between $3.5 \cdot 10^{9} \mathrm{Nm}^{-2}$ and $4.5 \cdot 10^{9} \mathrm{Nm}^{-2}$ ) of the elastic parameters that are stated in the manufacturer's data sheet [32].

Slightly extrapolating the fit results of the propagation speed $c_{B}$ to higher frequencies (Fig. 10), shows that the critical frequency $f_{c}$, for which the bending wave speed equals the speed of sound in air (at $20^{\circ}$ Celcius about $343 \mathrm{~ms}^{-1}$ ), is about $2600 \mathrm{~Hz}$ in both the $x$ - and $y$-directions. This estimate is confirmed by the measured sound reduction index coincidence dip in the 2500 and $3150 \mathrm{~Hz}$ 1/3rd octave bands (Fig. 7).

Apart from the waves propagating through the panels, waves could also exist which propagate through the studs at a higher propagation velocity. The problem, however, is that these waves are harder to measure. Being 


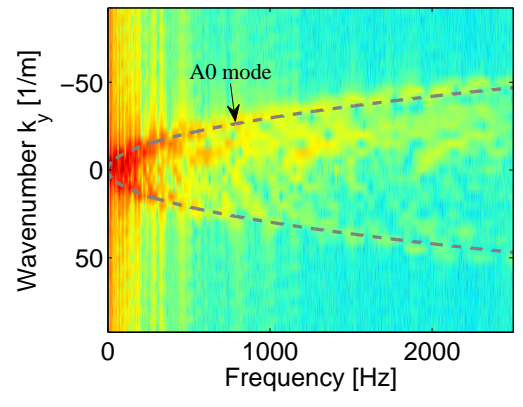

(a)

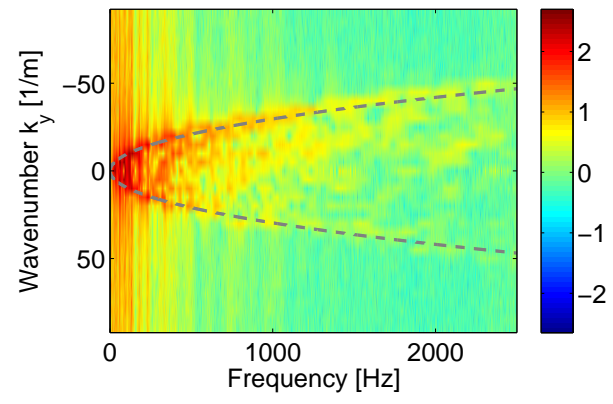

(b)

Figure 12: Dispersion plot in vertical direction showing $\hat{\tilde{v}}(\mathbf{k}, \omega)$ (Eq. 10p) on a logarithmic scale ( $\log _{10}$ of the absolute value of $\hat{\tilde{v}}(\mathbf{k}, \omega)$, arbitrary unit), using measurement points on the gypsum fiber boards at the position of the middle stud only. The grey dashed line is the theoretically predicted dispersion curve for the A0-mode. (a) Configuration 1; (b) configuration 4.

only indirectly excited by waves incident from the panels and to a great extent reflecting at the panel-stud interface, their amplitudes are weaker. In order to detect possibly excited higher order modes with a higher sensitivity, a one-dimensional dispersion measurement along a vertical line on the gypsum fiber boards at the position of the middle stud was performed. After applying a one dimensional spatial Fourier transform on the measurement data, $k-\omega$ dispersion plots are obtained. In Fig. 12 the dispersion results are shown for configuration 1 and configuration 4 . In these plots the theoretical wavenumber $k$ of the Lamb A0 mode is plotted additionally, which is based upon the bending wave model (Eq. 13) in a slightly different form:

$$
k_{B}=\frac{\omega}{c_{B}}=\left(\frac{m^{\prime \prime}}{B}\right)^{1 / 4} \sqrt{\omega}=\left(\frac{12 \rho\left(1-\nu^{2}\right)}{E h^{2}}\right)^{1 / 4} \sqrt{\omega}
$$

where we used the bending stiffness $B$ and mass per unit surface area $m^{\prime \prime}$ of the gypsum fibre boards, based upon the fit results depicted in Table 3 . From Fig. 12 it is thus seen that only the Lamb A0 mode (flexural wave) of the panel is detected by the measurement. Thus, symmetric or higher order modes of the studs are not visible, and the waves propagating through the panels dominate. 


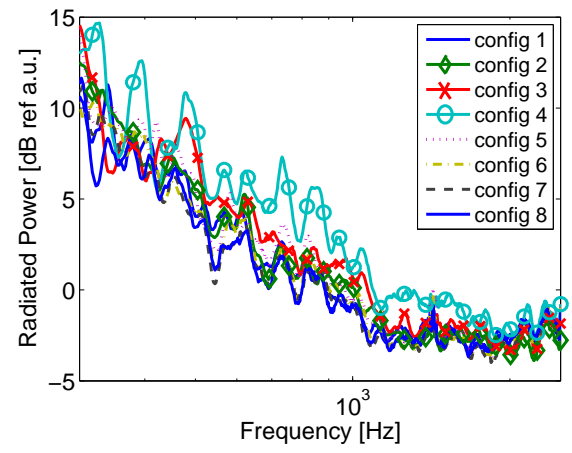

(a)

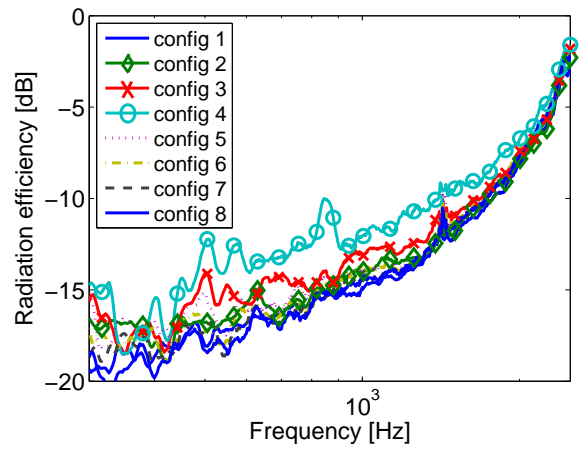

(b)

Figure 13: Laser Doppler vibrometry data based simulation results as function of frequency, narrow band (for a configuration description see Table 1). (a) Radiated sound power; (b) radiation efficiency.

\subsubsection{Sound power analysis and radiation efficiency analysis}

As explained in Section 2.2 the acoustic pressure at the vibrating panel can be calculated from the LDV measured vibrational panel response by means of a Rayleigh integral, without the influence of the acoustic modes of the receiving room [23]. The radiated sound power and the radiation efficiency of the vibrating building element were determined as a function of frequency (Fig. 13). The radiation efficiency for configuration 4 (7 rows of screws firmly fixed) is $2-5 \mathrm{~dB}$ higher over a broad frequency range, starting at $500 \mathrm{~Hz}$ and upwards up to about $2000 \mathrm{~Hz}$, as compared to the other configurations. The radiation efficiency is presented in $1 / 24$ th and $1 / 3 \mathrm{rd}$ octave bands in Fig. 14, showing the same significant differences in radiation efficiency for configuration 4.

The reason of the increased radiation efficiency can be explained as follows. Xie and Thompson [33] (which was originally due to [34]) give an expression for the radiation efficiency of a lightly damped plate:

$$
\sigma= \begin{cases}\frac{P c}{4 \pi^{2} S f_{c}} & \text { for } f<f_{c} \\ 0.45 \sqrt{\frac{P f_{c}}{c}} & \text { for } f=f_{c} \\ \left(1-\frac{f_{c}}{f}\right)^{-1 / 2} & \text { for } f>f_{c}\end{cases}
$$

where $P$ is the perimeter of the the plate and $S$ is the area of the plate. From this formula it can be seen that below the critical frequency $f_{c}$ the radiation 


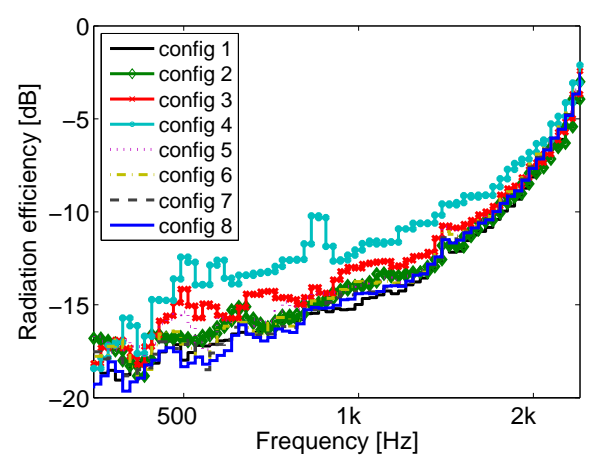

(a)

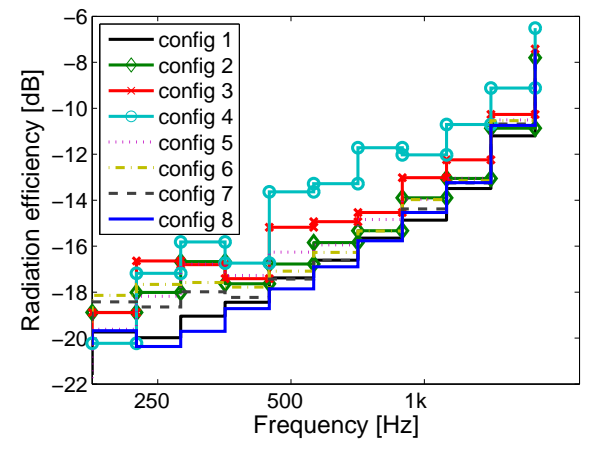

(b)

Figure 14: Laser Doppler vibrometry data based calculated radiation efficiency as function of frequency (for a configuration description see Table 1). (a) 1/24th octave band representation; (b) 1/3rd octave band representation.

efficiency is linearly proportional to the ratio $P / S$. The significant increase of the radiation efficiency for configuration 4 at frequencies starting at 500 $\mathrm{Hz}$ up to about $2000 \mathrm{~Hz}$, is because the effective perimeter of the whole panel is increased due to the fastening of the screws. Physically speaking, one could say that the end-effects are increased due to the fastening of the screws, which causes the acoustic cancellation below the critical frequency to be less effective, thus increasing the radiation efficiency for structure borne excitation.

\subsubsection{Operational deflection shapes (ODS) analysis}

The operational deflection shapes were determined by estimating the frequency response functions between the response of the structure at the grid of measurement positions and some reference signal. The force transducer of the impedance head was used as the reference signal. A multi-pass measurement approach was used [35] in which the frequency response functions were measured sequentially in time, employing the phase between the response at the different measurement points and the reference to reconstruct the phase between the individual responses. The estimations were done by taking 9 averages in the frequency domain.

In Fig. 15 the operational deflection shapes (ODS) are shown on a linear scale for a number of configurations. For instance, Figs 15(a) and 15(b) show the ODS of configuration $8(=1)$ (screws at bottom and top) and 


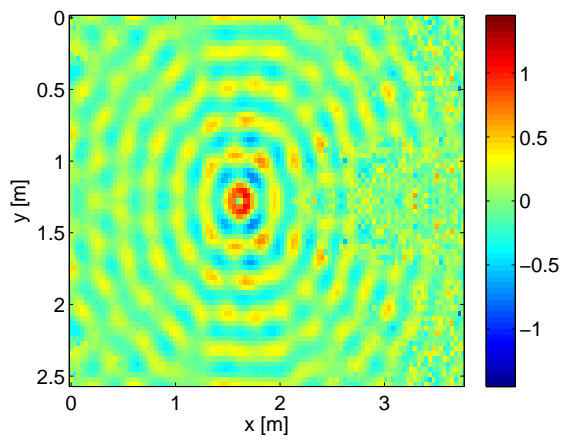

(a)

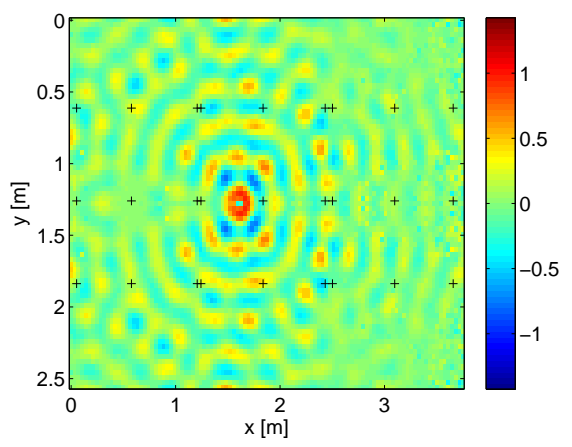

(c)

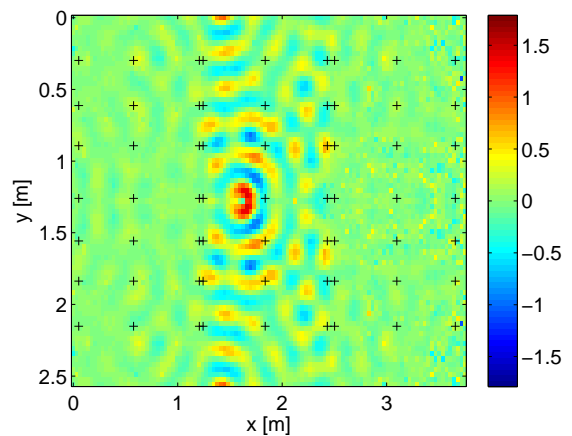

(b)

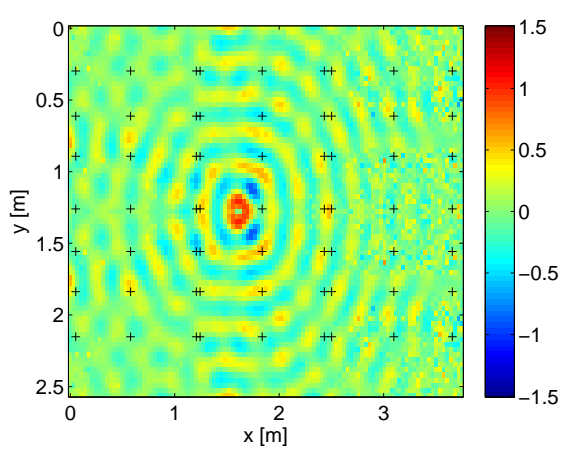

(d)

Figure 15: Operational Deflection Shapes (ODS) at $700 \mathrm{~Hz}$ (for a configuration description see Table 1). The displacements are presented on a linear scale (arbitrary unit), showing the real part of the motion at some point in time of the cycle. The + signs denote the position of the screws. (a) Configuration $8(=1)$; (b) configuration 4; (c) configuration 3; (d) configuration 5.

configuration 4 ( 7 rows of screws firmly fixed), respectively, both at $700 \mathrm{~Hz}$. For configuration $8(=1)$ (screws at bottom and top) the waves propagate radially in an undisturbed manner, away from the excitation point. The panel behaves like a uniform, free plate. For configuration 4 however $(7$ rows of screws firmly fixed), the vibration amplitude reduces significantly when crossing a column of screws. At other frequencies the behavior was found to be similar.

To illustrate that the panel fastening affects all frequencies (and not only the frequencies shown in Fig. 15), the time domain impulse responses 


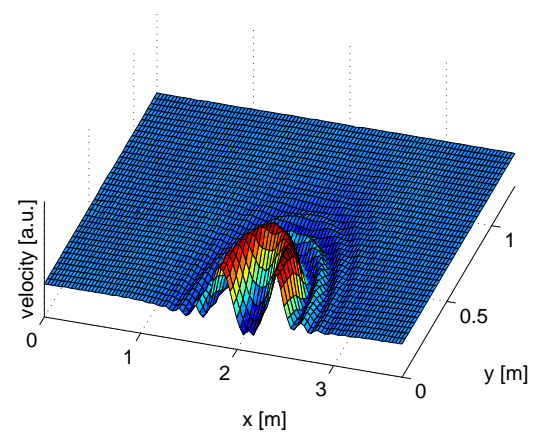

(a)

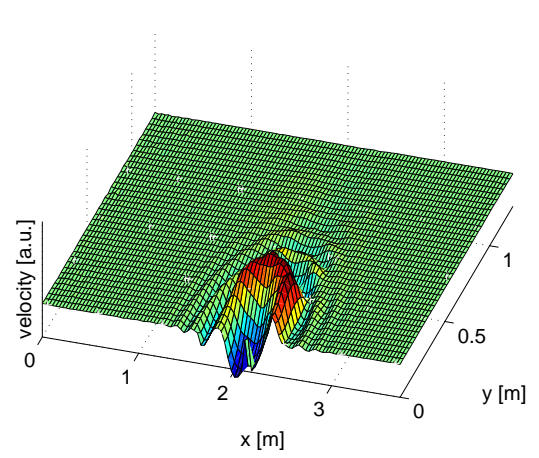

(c)

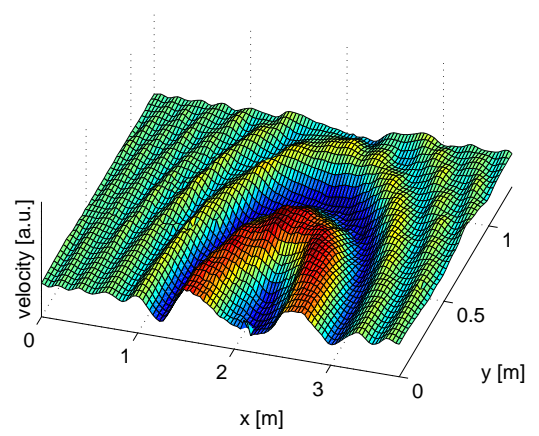

(b)

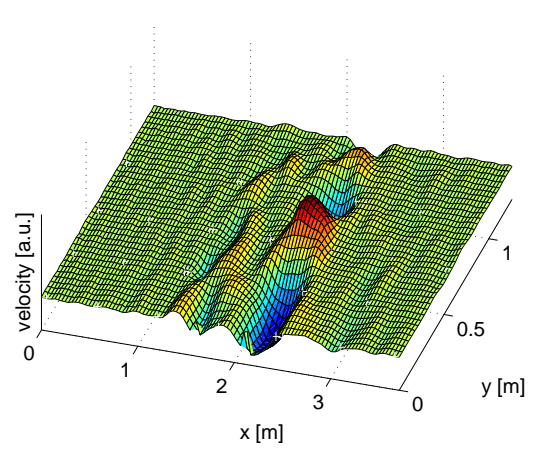

(d)

Figure 16: Time domain impulse responses for different configurations (for a configuration description see Table 1), presented on a linear scale (arbitrary unit). The graphs show the upper half part of the partition only. The + signs denote the position of the screws. (a) Configuration $8(=1)$, time: $0.0014 \mathrm{~s}$; (b) configuration 8 (=1), time: $0.0050 \mathrm{~s}$; (c) Configuration 4, time: $0.0014 \mathrm{~s}$; (d) configuration 4, time: $0.0050 \mathrm{~s}$

for different configurations were computed. This was done by transforming the frequency domain measurement data back to the time domain by means of an inverse Fourier transform. The time domain results for configuration 8 $(=1)$ (screws at bottom and top) and configuration 4 (7 rows of screws firmly fixed) are shown in Fig. 16. Physically speaking, the figure shows an impulse response function due to a 'virtual' impact at the shaker position. The shaker excited a wide range of frequencies, as during the experiment a white noise excitation was applied, with which the time domain impulse response could 


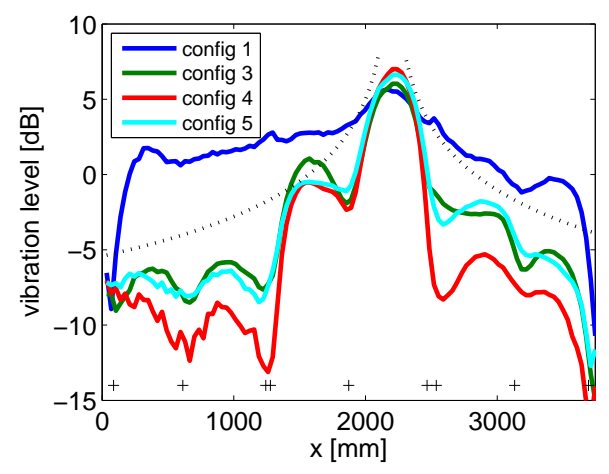

(a)

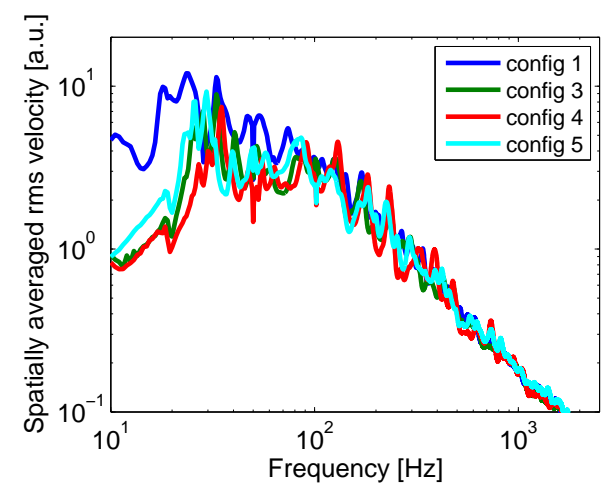

(b)

Figure 17: The panel vibration level for a number of panel configurations. (a) Frequency averaged and spatially averaged along the $y$-axis, $\left\langle v^{2}\right\rangle(x)$ (Eq. 16), as function of horizontal position $x$. The ' + ' signs indicate the $x$-coordinate position of the screws. The dashed curve shows the theoretical decay of a cylindrical wave traveling in a plate of infinite dimension. (b) Spatially averaged vibration level $\left\langle v^{2}\right\rangle$ (Eq. 17), as function of frequency.

be reconstructed with a reasonably good quality. It can be seen that for configuration $8(=1)$ (screws at bottom and top) the structural waves can freely propagate in the panels. However, for configuration 4 (7 rows of screws firmly fixed) the waves are retained in the first two bays which are excited by the shaker directly.

Calculating the spatially averaged mean-square velocity $\left\langle v^{2}\right\rangle(x)$, averaging along the vertical direction only, where

$$
\left\langle v^{2}\right\rangle(x)=\frac{1}{H} \int_{y=0}^{H}(v(x, y))^{2} d y
$$

and where $H$ is the dimension of the surface area in vertical $(y)$ direction, the result shown in Fig. 17(a) is obtained. In this figure a theoretical curve is added as well, showing the vibration levels of a cylindrical wave along a line (in a plate with infinite dimension), dropping in amplitude with increasing perimeters the further it travels. For configuration 8 and 1 (screws at bottom and top), the vibration level gradually decreases with increasing horizontal distance from the point of excitation, following only partly the theoretical curve. The deviations from the theoretical curve are due to reflections at 
the boundaries of the partition. For configuration 4 (7 rows of screws firmly fixed) a significant reduction of the vibration level occurs on the double column of screws, i.e. at approximately $x=1260 \mathrm{~mm}$ (Fig. 17(a)). This is the position where the gypsum fiber board butts are sealed by a jointing compound, and fixed to the studs with a double column of screws. A smaller but still significant reduction of the vibration level occurs when the waves need to pass a single column of screws, i.e. at approximately $x=1880 \mathrm{~mm}$ (Fig. 17(a)). So across a double column of screws a much higher reduction of the vibration level (about twice as high, expressed in $\mathrm{dB}$ ) occurs than across a single column of screws. Figure 17(a) also shows that loosening the screws with one half turn (configuration 5 as compared to configuration 4), or using half as many screws (configuration 3 as compared to configuration 4, both firmly fixed), reduces the reduction of the the vibration level across a column of screws by about the same amount; configuration 3 and configuration 5 behave about the same. Notice that in Section 4.1 it was also seen that these two configurations give the same single number rating

The structural vibration level in the mid bay of the partition are significantly higher for configuration 4 as compared to the other configurations. The vibration levels in the shaker-bay are about 3-4 dB higher as compared to configuration 8 (see Fig. 17(a)). This is due to the fact that in configuration 4 the waves are reflected by the firmly fixed fastening screw connections, causing an increased vibration level in the mid bay, as compared to configuration 1 (or 8) in which the waves can spread all over the panels without strong reflections. Note that in this experiment the excitation and measurement of the vibrational response was on the same side of the double wall panel.

Calculating the spatially averaged mean-square velocity $\left\langle v^{2}\right\rangle$ across the whole surface area $S$, where

$$
\left\langle v^{2}\right\rangle=\frac{1}{S} \int_{x} \int_{y}(v(x, y))^{2} d x d y
$$

the result shown in Fig. 17(b) is obtained, showing that there is not a significant difference of the overall vibration levels between the configurations.

From these observations (referring to the result shown in Fig. 17(a)), it is clear that the screws (and especially the double column of screws) have a large impact on the effective ratio of perimeter $P$ over area $S$, thus increasing the radiation efficiency, as explained in the previous sub-section. 


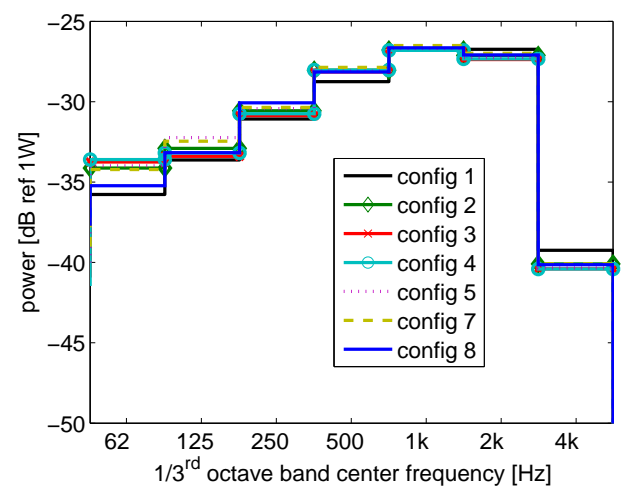

Figure 18: Mechanically injected active power (for a configuration description see Table 1).

\subsubsection{Measurement results of mechanically injected power}

The mechanically injected active power $\left\langle P_{m}\right\rangle_{t}$, as determined from the impedance head measurement data by means of Eq. (8), is presented in Fig. 18 in terms of full octave bands. The amount of mechanical power being injected for configuration 4 differs only approximately $1 \mathrm{~dB}$ as compared to the other configurations, when considering the $250 \mathrm{~Hz}$ octave band and higher octave bands. Hence, the amount of mechanical power injected for all configurations is approximately the same.

\subsubsection{Discussion of structure borne measurement results}

It is observed that the mechanically injected active power $\left\langle P_{m}\right\rangle_{t}$ as well as the spatially averaged mean-square velocity $\left\langle v^{2}\right\rangle$ across the whole surface area $S$ do not differ significantly for the different configurations, whilst the radiation efficiency $\sigma$ is about 3-5 dB higher for configuration 4 as compared to configuration 1 or 8 . According to theory $\left(\tilde{W}=\frac{1}{2} \sigma \rho c S\left\langle\tilde{v}_{n}^{2}\right\rangle\right.$, Eq. 7) the radiated sound power for structure borne excitation should thus be 3-5 dB higher for configuration 4 as well. This is indeed the case, as can be seen in Figure $13(\mathrm{a})$.

Using airborne excitation, the sound reduction index $R$ was measured to be significantly lower for configuration 4 as well, as compared to the other configurations. In terms of $R_{W}+C$ and $R_{W}+C_{t r}$ the differences between the best and worse case (configuration 4) was $9 \mathrm{~dB}$ with standard deviation of $3.4 \mathrm{~dB}$ (see Section 4.1). However, to link the measurement results as obtained by structure borne excitation and airborne excitation is non-trivial. 
In the case of acoustical excitation, the sound power radiated into the receiving room comprises contributions from forced waves and from resonance waves in the partition. The forced waves usually dominate below the coincidence frequency of the partition and the resonance waves above [21]. The sound power radiated by the partition due to a structure borne point excitation consists of contributions from the near-field vibrational components in the partition and from reverberant components [21]. Most often, when exciting a structure mechanically below the coincidence frequency, the contribution from the near-field vibrational components in the partition is negligible as compared to the reverberant components. When exciting airborne below the coincidence frequency, normally the waves mainly consist of forced waves. Provided these two assumptions apply, the following relationship holds [19] 1 .

$$
R+L_{N}=39.5+20 \log _{10} f-\Delta L_{n}-10 \log _{10} \frac{f_{c} \eta}{\sigma_{s t r}}
$$

where $L_{N}$ is the normalized impact noise level, defined by ISO10140-3:2010 [16], $\sigma_{s t r}$ is the radiation efficiency for structure borne excitation by means of the tapping machine, and $\eta$ is the structural loss factor of the partition. The correction term $\Delta L_{n}$ accounts for a reduced excitation force due to possible elastic layers that are applied on the structural-excitation-side of the partition, when using a tapping machine.

Although a relationship between structure borne transmission $\left(L_{N}\right)$ and airborne transmission $(R)$ exists, it is not straightforward to quantitatively exploit this relationship. The forces exerted on the partition by the shaker need to be related to the standardized excitation spectrum of a tapping machine, and knowledge is required about the structural loss factor and the radiation efficiency of the partition. Nevertheless, qualitatively one could say that when a partition transmits structure borne noise easily ( $L_{N}$ high), it is very likely according to Eq. 18 that the airborne sound insulation will be low as well ( $R$ low). Using structure borne excitation it was found that the radiation efficiency differs significantly between different configurations. There is a striking correspondence between the increased radiation efficiency and the reduced sound reduction index $R$ for configuration 4 as compared to

\footnotetext{
${ }^{1}$ The relationship for frequencies below the coincidence frequency given by Beranek in [21] (Eq. 11.173) is wrong. The correct relationship is given by Vér [19] (Eq. 18).
} 
the other configurations. The radiation efficiency is likely to play a comparable role in case of airborne excitation as well, which would partly explain the observed reduction of the sound reduction index $R$ for some configurations.

\section{Conclusions}

Standardized sound insulation measurements show that the airborne sound insulation of light weight structures are significantly affected by the number of screws used to fasten the panels to the studs, and the tightness of the screws. Using many screws and tightly fastening the screws reduces the weighted sound reduction index $R_{W}$ up to $10 \mathrm{~dB}$ as compared to either loosely fixing the screws or using a smaller number of screws. As the differences occur in the frequency range from 300 to $4000 \mathrm{~Hz}$, which range is crucial for speech privacy, the way building elements are fastened can have a large impact on its acoustic performance.

The physical mechanisms involved were investigated by means of laser Doppler vibrometry (LDV) measurements with the aim to enhance the understanding of the interactions in the zones around the screws. Using the LDV measurement data, the acoustic radiation efficiency and the radiated sound power of the partition were approximated by means of a Rayleigh integral. It was found that rigid fastening of the panels with many screws significant increases the radiation efficiency for structure borne excitation. Using know relations between airborne sound insulation and impact sound pressure level of a partition, it is argued that this increased radiation efficiency partly explains the reduced sound reduction index for airborne noise as well.

The increasing radiation efficiency can be explained by an increased contribution of end-effects referring to edge radiators of the panels with boundaries formed by the screws, thus effectively increasing the perimeter of the panel.

Loosening the screws, or using fewer screws, reduces the radiation efficiency, and significantly increases the sound reduction index of the partition.

The material properties of the panels were estimated from the dispersion measurements, employing the laser Doppler vibrometry measurement data, resulting in a Young's modulus of approximately $4.5 \cdot 10^{9} \mathrm{Nm}^{-2}$, which is very close to the value the manufacturer provided in the data sheet of the panels. From the estimated elastic parameters, the coincidence frequency of 
the panel was determined as approximately $2600 \mathrm{~Hz}$, which was confirmed by the coincidence dip in the sound reduction index at this frequency.

Configurations with typical arrangements of the screws show variations that can exceed the range of the sound insulation categories of the recently proposed and currently applicable classification schemes for dwellings (i.e. c.f. [8, 9]). This extent of uncertainty caused by workmanship supports the approach discussed in [36], where compulsory inspection and monitoring are considered to be indispensable for reliably ensuring the sound insulation performance of the buildings.

In order to decrease the variation due to workmanship it is necessary to provide construction guidelines with detailed technical specifications.

\section{Acknowledgements}

N.B. Roozen acknowledges support of the European Commission, Marie Curie Grant, FP7-PEOPLE-2011-IEF, Grant Agreement Number PIEF-GA2011-298278, Project acronym PAM, Project title "the Physics of Acoustic Materials". Part of this research has been performed in a framework of COST Action TU0901, STSM reference number: COST-STSM-TU090112920. Jakub Benklewski from TGM Vienna is acknowledged for his great help in carrying out the measurements. Philip Degreef and Werner Neefs from ATF KULeuven are acknowledged for their help with the electronics and mechanics of the Thorlabs dual-axis scanning mirror system. Vojtech

Chmelik from STU Bratislava is acknowledged for making the technical drawings of the test specimen. 


\section{Appendix A. Weighted linear least squares fit of measurement data on an ellipse}

An ellipse having its center at $(x, y)=(0,0)$, with a radius $a_{x}$ and $a_{y}$ in $x$ and $y$-direction, respectively, is mathematically described by

$$
\left(\frac{x}{a_{x}}\right)^{2}+\left(\frac{y}{a_{y}}\right)^{2}=1
$$

or, written differently

$$
b_{x} x^{2}+b_{y} y^{2}=1
$$

where $b_{x}=\left(\frac{1}{a_{x}}\right)^{2}$, and $b_{y}=\left(\frac{1}{a_{y}}\right)^{2}$. The linear least square fit of measurement data of $n$ points, collected in the column vectors $\mathbf{x}=\left\{x_{1}, x_{2}, \ldots, x_{n}\right\}^{T}$ and $\mathbf{y}=\left\{y_{1}, y_{2}, \ldots, y_{n}\right\}^{T}$ can be written as

$$
\left\{\begin{array}{l}
b_{x} \\
b_{y}
\end{array}\right\}=\left[\begin{array}{cc}
x_{1}^{2} & y_{1}^{2} \\
x_{2}^{2} & y_{2}^{2} \\
\vdots & \vdots \\
x_{n}^{2} & y_{n}^{2}
\end{array}\right]^{+}\left\{\begin{array}{c}
1 \\
1 \\
\vdots \\
1
\end{array}\right\}
$$

where ${ }^{+}$in this case denotes the pseudo inverse of a matrix. Written in matrix notation:

$$
\mathbf{b}=\mathbf{X}^{+} \mathbf{y}=\left(\mathbf{X}^{T} \mathbf{X}\right)^{-1} \mathbf{X}^{T} \mathbf{y}
$$

where $\mathbf{b}=\left\{b_{x}, b_{y}\right\}^{T}, \mathbf{X}$ as defined in Eq. A.3), and $\mathbf{y}=\{1,1, \ldots, 1\}^{T}$

The weighted linear least squares fit is given by

$$
\mathbf{b}=\left(\mathbf{X}^{T} \mathbf{W} \mathbf{X}\right)^{-1} \mathbf{X}^{T} \mathbf{W} \mathbf{y},
$$

where the matrix $\mathbf{W}$ is a diagonal matrix with weighting terms. The dimension of matrix $\mathbf{W}$ is $n \times n, n$ being the number of measurement points. 


\section{References}

[1] A.C.C. Warnock, W. Fasold, Sound Insulation: Airborne and Impact, in M.J. Crocker (Ed.), Encyclopedia of Acoustics, Vol. 3, John Wiley \& Sons, Inc., New York, 1997, pp. 1129-1160.

[2] C. Hopkins, Sound Insulation, Elsevier Ltd., Oxford, 2007.

[3] R.A. Novak, Sound Insulation of Lightweight Double Walls, Applied Acoustics. 37 (1992) 281-303.

[4] J. Nurzynski, Sound Insulation of Lightweight Plasterboard Walls, Proceedings 17th International Congress on Acoustics, Rome 2001.

[5] H. Muellner, I. Plotizin: How 'secondary' details of the construction and workmanship effect the airborne sound insulation of plasterboard walls. Proceedings of Internoise, The Hague, The Netherlands, 27-30 August, 2001, 1133-1136.

[6] H. Muellner, I. Plotizin, Beeinträchtigung des Schallschutzes von Gipskartonständerwänden durch "sekundäre" Wanddetails und Verarbeitungsqualität (Influence on the airborne sound insulation properties of gypsum plasterboard walls due to minor construction details and workmanship), Proceedings DAGA Bochum 2002

[7] H. Muellner, I. Plotizin, The Influence of the Screw Position on the Airborne Sound Insulation of Plasterboard Walls, Proceedings ForumAcusticum Seville 2002

[8] B. Rasmussen, E. Gerretsen, Proposal for an Acoustic Classification Scheme for Housing, in B. Rasmussen, M. Machimbarrena, (Eds.), COST Action TU0901 - Towards a common framework in building acoustics throughout Europe, 2013, pp. 75-95.

[9] OENORM B 8115-5: 2012 Sound insulation and room acoustics in building construction - Part 5: Classification, Austrian Standards Institute, Vienna.

[10] J.D. Quirt, A.C.C. Warnock, J.A. Birta: Summary report for consortium on gypsum board walls: sound transmission results. National Research Council Canada, Internal report IRC-IR-693, 
Institute for Research in Construction, Canada, October 1995. http://doi.org/10.4224/20375264

[11] R.J.M. Craik, R.S. Smith: Sound transmission through lightweight parallel plates, Part I: airborne sound. Appl. Acoust. 61 (2000) 223-245.

[12] S. Schoenwald, B. Zeitler, T.R.T. Nightingale, Investigation of flanking sound transmission in lightweight building structures using a scanning laser vibrometer, Euronoise 2009, Edinburgh, October 26-28, 2009.

[13] A.R. Mayr, B.M. Gibbs, Point and transfer mobility of point-connected ribbed plates, Journal of Sound and Vibration, 330 (2011) 47984812

[14] V. Hongisto, M. Lindgren, R. Helenius, Sound Insulation of Double Walls An Experimental Parametric Study. Acta Acustica united with Acustica 88.6 (2002): 904-923.

[15] A. Uris, J. Sinisterra, J.M. Bravo, J. Llinares, H. Estelles, Influence of screw spacings on sound reduction index in lightweight partitions, Applied Acoustics 63 (2002) 813-818

[16] International Organization for Standardization ISO 10140:2010 Acoustics - Laboratory measurement of sound insulation of building elements - Part 1: Application rules for specific products, - Part 2: Measurement of airborne sound insulation, - Part 3: Measurement of impact sound insulation, - Part 4: Measurement procedures and requirements, - Part 5: Requirements for test facilities and equipment

[17] International Organization for Standardization ISO 717-1:2013 Acoustics - Rating of sound insulation in buildings and of building elements - Part 1: Airborne sound insulation

[18] M. Heckl, E.J. Rathe, Relationship between the Transmission Loss and the Impact?Noise Isolation of Floor Structures, Journal of the Acoustical Society of America Vol. 35, No. 11 (1963) 18251830.

[19] L. Vér, István, Relation between the normalized impact sound level and sound transmission loss, The Journal of the Acoustical Society of America, Vol. 50, no. 6A (1971), 1414-1417. 
[20] L. Cremer, M. Heckl, E.E. Ungar. Structure-borne sound, SpringerVerlag 1988

[21] L.L. Beranek, Noise and vibration control. New York; McGraw-Hill; 1971

[22] W. Kropp, A. Pietrzyk, T. Kihlman, On the meaning of the sound reduction index at low frequencies, Acta Acustica, Vol. 2, 1994, pp 379392

[23] N.B. Roozen, L. Labelle, M. Rychtáriková, C. Glorieux, Determining radiated sound power of building structures by means of Laser Doppler vibrometry, Journal of Sound and Vibration, 2015, DOI: http://dx.doi.org/10.1016/j.jsv.2015.02.029, open access: https://lirias.kuleuven.be/bitstream/123456789/484063/ 3/Determining+radiated+sound+power+Revision2b.pdf

[24] J.W.S. Rayleigh, The Theory of Sound, Second ed., Vol. 2. New York: Dover Publications; 1945.

[25] F.J. Fahy, Sound and Structural Vibration: Radiation, Transmission and Response. Academic Press, London, 1985.

[26] J.S. Lamancusa, Numerical optimization techniques for structuralacoustic design of rectangular panels, Computers \& Structures, Volume 48, Issue 4, 17 August 1993, Pages 661-675.

[27] J.W. Verheij, Cross spectral density methods for measuring structure borne power flow on beams and pipes, Journal of Sound and Vibration (1980) 70(l), 133-138

[28] B. Rasmussen, M. Machimbarrena, (Eds.). Building acoustics throughout Europe. Volume 1: Towards a common framework in building acoustics throughout Europe, Chapter 2: Existing Sound Insulation Performance Requirements and Classification Schemes For Housing Across Europe. DiScript Preimpresion, S. L. (2014)

[29] T.R.T. Nightingale, R.E. Halliwell, G. Pernica, Estimating in-situ material properties of a wood joist floor: Part 1 - Measurements of the real part of bending wavenumber and modulus of elasticity, Building Acoustics, Volume 11, Number 3, 2004, pp. 175-196. 
[30] S. Kurra, Comparison of the models predicting sound insulation values of multilayered building elements, Applied Acoustics 73 (2012) 575589.

[31] R. Salenbien, R. Côte, J. Goossens, P. Limaye, R. Labie, and C. Glorieux, Laser-based sur-face acoustic wave dispersion spectroscopy for extraction of thicknesses, depth, and elastic parameters of a subsurface layer: Feasibility study on intermetallic layer structure in integrated circuit solder joint, Journal of Applied Physics 109, 093104 (2011)

[32] http://www.rigips.at/fileadmin/Rigips_Daten/ Produktdatenblaetter_Platten_englisch/ engl_PDB_Rigidur_H_12_5.pdf (Accessed June 2014)

[33] G. Xie, D.J. Thompson, C.J.C. Jones The radiation efficiency of baffled plates and strips, Journal of Sound and Vibration, 280 (2005) 181-209.

[34] G. Maidanik, Response of ribbed panels to reverberant acoustic fields, Journal of the Acoustical Society of America 34 (1962) 809826.

[35] N.B. Roozen, Q. Leclère, C. Glorieux, M. Rychtáriková, A global error estimator for the uncertainty of a multi-channel spectral analysis, Applied Acoustics 87 (2015) 57-63, doi: http://dx.doi.org/10.1016/j. apacoust.2014.06.007, open access: https://lirias.kuleuven.be/ bitstream/123456789/458822/3/Globalerrorestimator.pdf

[36] S. Smith, J. Antonio, Monitoring \& Testing Sound Insulation Performance in New Homes in Europe, in B. Rasmussen, M. Machimbarrena, (Eds.), COST Action TU0901 - Towards a common framework in building acoustics throughout Europe, 2013, pp. 157-165. 